\title{
Using County Typologies to Inform Job Tax Credit Policy in Georgia ${ }^{+}$
}

\author{
Clifford A. Lipscomb and Rinas V. Kashbrasiev*
}

\begin{abstract}
Some problems with the Georgia job tax credit program have been outlined as have some potential remedies. In this paper, we analyze Georgia's job tax credit policy through a county typology lens. County typologies are created using factor analysis of the most recently available demographic, socioeconomic, amenity, industrial, and fiscal data to endogenously locate different aggregations of Georgia counties. Then, we visually inspect the different county aggregations for clusters of counties. Finally, we illustrate the utility of these county types to recommend policy changes in the State's policy on job tax credit tiers.
\end{abstract}

Key Words: job tax credit, aggregation, factor analysis

JEL Classifications: C43, R38, R58

\section{INTRODUCTION}

The purpose of this paper is to analyze Georgia's job tax credit policy through a "county typology lens" by starting with a maximum diversity profile for each county in the State of Georgia. Then, using factor analysis, this paper seeks to aggregate counties into groups based on the data employed, the purpose of which is to inform state policy on job tax credits offered to businesses that create jobs in particular counties. While it is common in regional science to require geographical areas to be aggregated contiguously, we do not impose this requirement on the final outcome. In fact, we hope to show that some counties are similar enough in these many dimensions to warrant being grouped together into "types" despite their geographic location. In this way, the job tax credit policy can be applied uniformly to counties that are similar to each other. In the end, what we find is that seven different types of counties emerge from the data. As we expect, some types comprise counties that are contiguous, whereas other types comprise counties that are not contiguous. We suspect that these results will be useful to state-level officials interested in economic development and planning, particularly those within the Georgia Department of Economic Development and the Department of Community Affairs, which offer tiers of job tax credits to different counties based on a set rubric (as discussed in Ihlanfeldt and Sjoquist, 2001). The results presented here suggest that the allocation of tax credits using the current four-tier system is less than optimal and may need to be revised according to these statistical aggregations of counties.

\footnotetext{
${ }^{+}$The authors thank Pamela Goshay and Beverly Bennett at the Georgia Department of Revenue for providing access to the job tax credit data. Also, we thank Michael A. Shiroya for excellent research assistance in the preparation of the data. This paper was completed with assistance from the Valdosta State University Faculty Development Fund. It was also completed while Kashbrasiev was a visiting scholar at Valdosta State University for the 2007-2008 academic year, on leave from Kazan State University and the Institute of Regional Socio-Economic Research, The Tatar Humanitarian Educational State University.

* Lipscomb is an Assistant Professor in the Department of Marketing and Economics at Valdosta State University. Kashbrasiev is an Associate Professor in the Department of Economic Geography and Regional Analysis at Kazan State University in Kazan, Russia.

Contact Information: Clifford Lipscomb, 1500 N. Patterson St., Valdosta, GA 31698. E-mail: calipscomb@valdosta.edu.
}

(C) Southern Regional Science Association 2010.

ISSN 1553-0892

SRSA, 1601 University Avenue, PO Box 6025, Morgantown, West Virginia 26506-6025, USA. 
The rest of the paper is outlined as follows. First, we describe Georgia's use of the job tax credit as an economic development tool. Next, we describe the data and methods employed in this analysis. Then, we determine the county typologies through statistical aggregation. Next, the results of the factor analysis will be presented. Then, we discuss the results and their implications for the general study of regional science. We end with some conclusions about the future of the job tax credit policy.

\section{GEORGIA'S JOB TAX CREDIT POLICY}

The State of Georgia has a greater number of counties relative to neighboring states. Its total number of counties (159) is second only to Texas (254). As with any unit of analysis, the principles of precise measurement suggest that it needs to demonstrate within-type homogeneity (sameness) and across-type heterogeneity (differentiation). The relatively large number of counties in Georgia may affect generalizability of the results of this study. If neighboring counties have very similar characteristics, then some degree of clustering of counties into "supercounties" may be theoretically valid, especially if the provision of public services to "supercounty" residents can be achieved at a lower marginal cost. At the other extreme, neighboring counties may be so different in multiple dimensions that any kind of regional aggregation based on adjacency or contiguity is not theoretically valid. One example might be the use of neighboring counties' populations to achieve Metropolitan Statistical Area (MSA) status when the neighboring counties have a completely different employment mix, different levels of disposable income, and different fiscal capacities. These two extremes describe the aggregation issue common in regional science, outlined in original works by Samuelson (1954) and Tiebout (1956). In this study, if counties tend to cluster, it is likely that the results will differ if we used an aggregation procedure on fewer, but larger counties. In the Discussion section, we compare our results with other attempts at county aggregation.

The Georgia Department of Community Affairs (DCA) is the state organization that determines the different levels of job tax credits available to counties as economic development tools. Early research on Georgia's economic development programs by Ihlanfeldt (1995) finds some laudable features of the programs. Additional research by Faulk (2002) suggests a significant employment impact of the Georgia Job Tax Credit system; firms taking the tax credit created 23 to 28 percent more jobs than eligible firms not taking the credit during the 1993 to 1995 period. These tax credits have persisted in Georgia despite the evidence suggesting that tax incentives like the job tax credit exclude from participation the majority of businesses in the state and shift state fiscal burdens from one class of taxpayers to another (Morse, 1996). Below we discuss the rubric used by DCA to determine the job tax credit tiers and we offer an alternative approach that incorporates more data in a systematic examination of county differences in terms of economic development capabilities.

Certain conditions must be met before a business is eligible for a job tax credit. For example, a business or headquarters of a business engaged in manufacturing, warehousing and distribution, processing, telecommunications, tourism, or research and development is automatically eligible for the job tax credit, which the business receives in years two through six if, say, it creates new jobs in year one. Retail businesses are eligible for a job tax credit only if they locate within a county that is recognized and designated as one of the forty least developed counties in the State. In other industries, a minimum number of new full-time jobs must be created in order to qualify for job tax credits. 
According to Ihlanfeldt and Sjoquist (2001), prior to 2001, job tax credit tiers in Georgia (three of them) were based on four criteria (including the average weekly manufacturing wage). Today, there is a four-tier system that is based only on the other three criteria: highest unemployment rate in the previous 36 months, lowest per capita income in the previous 36 months, and the highest percentage of residents whose incomes are below the federal poverty level in the previous 36 months. Qualified businesses in Tier 1 counties are those that are eligible for the highest job tax credits $(\$ 3,500$ per job created); Tier 2 counties allow qualified businesses to be eligible for $\$ 2,500$ per job created; qualified businesses in Tier 3 counties are eligible for $\$ 1,250$ per job created; and Tier 4 counties allow qualified businesses to be eligible for $\$ 750$ per job created. Ihlanfeldt and Sjoquist outline some benefits of and problems with an earlier version of Georgia's job tax credit policy. They discover from meetings with the Governor's staff and the Office of Planning and Budget that "job creation and retention and improvement in job quality were the key objectives" (p. 219). Interestingly, these key objectives still are not used explicitly in the tier designation criteria; the current criteria for determining tier status do not account for the ability of counties to improve job quality or retain new jobs. So, it is possible that counties with the ability to offer businesses higher job tax credits (and potentially more local economic incentives like land at a heavily discounted price) will not recruit more businesses because of deficiencies in physical infrastructure (roads, water, and sewer,), a lack of local amenities that are attractive to new job recruits, a weak Chamber of Commerce, a weak industrial or development authority, or a lack of development motivation in local governments.. Unfortunately, due to data limitations, the ability of counties to recruit and retain new businesses cannot be included in this analysis; we can observe only variables related to socioeconomic characteristics in the counties, demographic characteristics, fiscal characteristics, amenity characteristics, and industry characteristics. Future research in this area will focus on the influence of demonstrated ability to recruit and retain new businesses on tier determination.

\section{DATA AND METHODS}

Table 1 shows descriptive statistics for the variables used in the determination of county typologies. In this paper, the county is the unit of analysis. Notice that five distinct categories of variables are used in the analysis - socioeconomic variables, fiscal variables, amenity variables, industry variables, and demographic variables. All of these data were obtained from the Georgia Statistics System maintained by the University of Georgia (2008).

Included in the socioeconomic category are lottery sales per capita, bankruptcy filings per 100,000 population, average weekly wage, median rent, median property value, and homeownership rate. The years for these variables are the most recently available.

Included in the fiscal category are total deposits per capita, government expenditures per capita, a measure of fiscal capacity, countywide millage rate, local government direct general expenditures for health and hospitals, and SPLOST (special purpose local option sales tax) monies raised within the county in 2004. Fiscal capacity is the ability of counties to generate revenue. The fiscal capacity of local governments, calculated by the Georgia Department of Community Affairs (DCA), represents the revenue per capita that would be raised in 2000 by a given revenue structure expressed as a percentage of the state average. Identifying the fiscal capacity gives local governments a good idea of the different programs and services that they will be able to provide to their citizens relative to the rest of the state. A fiscal capacity index

(C) Southern Regional Science Association 2010. 
TABLE 1. Variables Used in Typology Determination Process

\begin{tabular}{|c|c|c|}
\hline Group & Description & Name \\
\hline SocioEcon & $\begin{array}{l}\text { Lottery Sales per capita, FY2006 } \\
\text { Mean }=402.37 \text {; Standard Deviation }=258.14 \\
\text { Bankruptcy filings, } 1 \text { yr as of } 12 / 2005 \text {, rate per } 100,000 \text { pop } \\
\text { Mean }=8.58 ; \text { Standard Deviation }=2.63 \\
\text { All Industries, Average Weekly Wage in Dollars, } 2005 \\
\text { Mean }=539.27 ; \text { Standard Deviation }=95.75 \\
\text { Median rent, 2000 } \\
\text { Mean }=434.42 ; \text { Standard Deviation }=128.03 \\
\text { Median property value, } 2000 \\
\text { Mean }=81555.97 ; \text { Standard Deviation }=27393.03 \\
\text { Homeownership rate, } 2000 \\
\text { Mean }=73.92 ; \text { Standard Deviation }=8.50\end{array}$ & $\begin{array}{l}\text { LOTTERY } \\
\text { BANKRUPT } \\
\text { AVGWAGE } \\
\text { MEDRENT } \\
\text { PROPVAL } \\
\text { OWNRATE }\end{array}$ \\
\hline Fiscal & $\begin{array}{l}\text { Total Deposits per capita, } 2005 \\
\text { Mean }=12611.25 ; \text { Standard Deviation }=7164.88 \\
\text { Government Expenditures per capita, } 2002 \\
\text { Mean }=2733.02 ; \text { Standard Deviation }=826.94 \\
\text { Fiscal Capacity (ability to raise revenues), } 2005 \\
\text { Mean }=85.98 ; \text { Standard Deviation }=23.81 \\
\text { Millage rate, county wide, } 2005 \\
\text { Mean }=27.11 ; \text { Standard Deviation }=5.32 \\
\text { Local Government Direct general expenditures for health and } \\
\text { hospitals (in 000s), 2002 } \\
\text { Mean }=23510.45 ; \text { Standard Deviation }=71200.29 \\
\text { Special Purpose Local Option Sales Tax (SPLOST) revenues } \\
\text { (in 000s), 2004 } \\
\text { Mean }=6462.86 ; \text { Standard Deviation }=17082.47\end{array}$ & $\begin{array}{l}\text { PCDEPOSIT } \\
\text { PCGOVT } \\
\text { FISCAL } \\
\text { MILLAGE }\end{array}$ \\
\hline Amenity & $\begin{array}{l}\text { Area of County Covered in Water (in Square Miles), } 2000 \\
\text { Mean }=9.55 ; \text { Standard Deviation }=26.47 \\
\text { School Pupil-to-Teacher Ratio, } 2005 \\
\text { Mean }=14.58 ; \text { Standard Deviation }=1.11 \\
\text { Percentage of schools achieving Annual Yearly Progress, } \\
\text { 2005/2006 } \\
\text { Mean }=75.93 ; \text { Standard Deviation }=23.38 \\
\text { Total Index Crime Rate per } 100,000 \text { Population, } 2005 \\
\text { Mean }=2639.66 ; \text { Standard Deviation }=1887.34 \\
\text { Number of Hazardous Waste Sites, } 2006 \\
\text { Mean }=2.88 ; \text { Standard Deviation }=6.28 \\
\text { Physicians, Rate per } 100,000 \text { population, } 2004 \\
\text { Mean }=114.26 ; \text { Standard Deviation }=98.01\end{array}$ & $\begin{array}{l}\text { WATER } \\
\text { STRATIO } \\
\text { AYP0506 } \\
\text { CRIME } \\
\text { HAZWASTE } \\
\text { DOCTORS }\end{array}$ \\
\hline
\end{tabular}

Southern Regional Science Association 2010. 
TABLE 1. Variables Used in Typology Determination Process (continued)

\begin{tabular}{|c|c|c|}
\hline Group & Description & Name \\
\hline Industry & $\begin{array}{l}\text { HHI Index of Industrial Mix, } 2005 \\
\text { Mean }=.16 \text {; Standard Deviation }=.07 \\
\text { Number of Harvested Cropland Acres, } 2002 \\
\text { Mean }=20413.74 ; \text { Standard Deviation }=24051.77 \\
\text { Retail Sales, Total Pull Factor, 2005 } \\
\text { Mean }=.81 \text {; Standard Deviation }=.43 \\
\text { Number of Building Permits, } 2006 \text { (from Census Bureau) } \\
\text { Mean = 655.34; Standard Deviation }=1812.24 \\
\text { Number of Public General Aviation Airports, } 2006 \\
\text { Mean = .66; Standard Deviation }=.59\end{array}$ & $\begin{array}{l}\text { INDMIX } \\
\text { CROPLAND } \\
\text { RETPULL } \\
\text { BLDGPERM } \\
\text { AIRPORTS }\end{array}$ \\
\hline Demographic & $\begin{array}{l}\text { HHI Index of Buying Power (by race), } 2006 \\
\text { Mean }=.69 ; \text { Standard Deviation }=.13 \\
\text { Population Density per Square Mile, } 2005 \\
\text { Mean }=180.36 \text {; Standard Deviation }=362.96 \\
\text { Unemployment Rate, } 2005 \\
\text { Mean }=5.66 \text {; Standard Deviation }=1.35 \\
\text { Percentage of Population that did NOT complete high school, } \\
2000 \\
\text { Mean }=29.29 \text {; Standard Deviation }=7.54 \\
\text { Percentage of Votes for President cast Republican in } 2004 \\
\text { General Election } \\
\text { Mean }=59.35 \text {; Standard Deviation }=11.24 \\
\text { Total Active Registered Voters (as of } 11 / 2006 \text { ) } \\
\text { Mean }=27728.47 \text {; Standard Deviation }=59499.05\end{array}$ & $\begin{array}{l}\text { BUYPOWER } \\
\text { POPDEN } \\
\text { UNEMPLOY }\end{array}$ \\
\hline
\end{tabular}

number less than 100 indicates that county revenues are less than the state average; greater than 100 indicates that county revenues are greater than the state average.

Included in the amenity category are the area of the county covered in water, the local school pupil-teacher ratio, the percentage of schools achieving Annual Yearly Progress (AYP), an index of total crime per 100,000 population, the number of hazardous waste sites, and the number of physicians per 100,000 population. By using these variables, we tried to capture the different kinds of amenities (natural amenities like water) and disamenities that may be responsible for in-migration and out-migration, respectively. The crime and hazardous waste site variables are measures of disamenities, whereas water coverage, the pupil-to-teacher ratio, AYP achievement, and density of physicians are relative measures of "attraction."

Included in the industry category are a Herfindahl-Hirschman Index (HHI) of industrial mix [using North American Industry Classification System (NAICS) employment figures] ${ }^{1}$, the

\footnotetext{
${ }^{1}$ The employment HHI is based on 14 industries: Agriculture/Forestry/Fisheries; Construction; Manufacturing; Government; Wholesale Trade; Retail Trade; Transportation and Warehousing; Information; Finance/Insurance; Professional/Scientific/Technical Services; Administrative/Waste Services; Health Care/Social Services; Accommodations/Food Services; and All Other Services.
}

(C) Southern Regional Science Association 2010. 
number of harvested cropland acres, the total retail sales pull factor, the number of building permits, and the number of public general aviation airports. The HHI is calculated as:

$$
\text { (1) } H H I_{e}=\frac{\left(\sum_{i=1}^{14} \text { employ }_{i}^{2}\right)}{10000} \text {. }
$$

An HHI equal to one indicates that all employees in the county are located in a single industry $\left(\right.$ employ $_{i}=100$ percent $)$; an $\mathrm{HHI}=.07$ indicates that employment is equally dispersed across the 14 industries.

Included in the demographic category is an HHI of buying power among three races/ethnicities, population density per square mile, county unemployment rate, percentage of population that has not completed high school, the percentage of votes cast for the Republican Presidential candidate in 2004, and the total number of active registered voters. The HHI, defined as:

$$
H H I_{b}=\frac{\left(\sum_{i=1}^{3} \text { buypower }_{i}^{2}\right)}{10000}
$$

measures the concentration of disposable income (unadjusted for inflation) across these groups in each county. An HHI equal to 1 indicates that one race/ethnic group has all of the disposable income (buypower $_{i}=100$ percent) in a given county whereas a HHI $=.33$ indicates that disposable income is evenly dispersed across the three groups [i.e. all races/ethnicities (White, Black, and Hispanic) control 33.3 percent of the disposable income]. ${ }^{2}$

We expect a priori that some dependence exists between tier designation and county type because some of the same variables are used in both processes. Descriptive statistics within each tier (available upon request) suggest that counties with the ability to offer higher job tax credits are not growing as fast in terms of population as counties with fewer job tax credits. Over the same time period (2000 to 2005), however, Tier 1 counties have the highest percentage increase in per capita income (11.3 percent), whereas Tier 4 counties have the lowest (4.3 percent). This result seems to follow the intent of the job tax credit - to assist economically weak counties and certain industries. From another perspective, this may signal a set of perverse incentives that face counties in Tiers 3 and 4; since these counties will not receive as large a tax credit for each job created, they need to work harder to secure other incentives (like OneGeorgia grants, etc.) for businesses seeking to locate to these particular counties. One possible option to be discussed later is to decrease the difference in job tax credit dollars available per job created.

\footnotetext{
${ }^{2}$ Recent research by Humphries (2007, p. 1) suggests that data on the buying power of different races and ethnicities are useful to measure "the relative vitality of geographic markets." The Herfindahl-Hirschman Index is used to synthesize data on three different races/ethnic groups into a single metric that measures buying power concentration. This is consistent with the Herfindahl indices used in the political science literature by Putnam (2007) and Maxwell and Winters (2004). One justification is that Hispanics' expenditure habits are so different from non-Hispanics; they have lower average income levels but spend more on groceries, telephone services, furniture, clothing, and footwear than non-Hispanics, according to the 2007 Consumer Expenditure Survey. Even though, technically, Hispanics may be of any race, the variables used here are mutually exclusive (e.g. Hispanic disposable income is not also captured in the non-Hispanic White and non-Hispanic Black categories). This method is useful as it reduces the number of variables used in the factor analysis and it accounts for counties that have relatively higher shares of disposable income concentrated in Hispanic households (Whitfield County, for example), which is something that a simple Black/White distinction might overlook.
} 
In addition, we see an increase in millage rates in counties that have the ability to offer more job tax credits. Coupled with the other correlations, this may suggest that slower population growth and slower per capita income growth are associated with the need to increase millage rates, especially in counties where the cost to run local government is increasing at a faster rate than the ability of the county to raise revenues. Also, we observe that high school completion rates increase, population density increases, fiscal capacity increases, and (as expected) unemployment rates decrease as we move from Tier 1 counties to Tier 4 counties, respectively. These relationships suggest that there is a strong urban-rural distinction between counties based on these variables, which is supported by the fact that 71 counties in the revised Tier 1 account for only 14.4 percent of the state's population (Ihlanfeldt and Sjoquist, 2001).

\section{FACTOR ANALYSIS OF GEORGIA COUNTIES}

Researchers a priori do not know how many different county aggregations exist in Georgia, nor do they know what comprises the types. For these reasons, county types in this paper are defined endogenously through a statistically based sorting process that uses data on many different facets of a county. This responds to a concern in the economics literature raised by Palmquist (2004), who argues that there are some fairly serious efficiency losses when a researcher pre-sorts observations into a pre-assigned number of discrete categories based on demographics alone (income, age, education, etc.); this is a concern if the researcher relies on these pre-assigned aggregations to measure differences between county types for policy prescription purposes. Exogenous pre-assignment sacrifices much of the data available to the researcher as it imposes ad hoc aggregations of the counties. In this study, both the number of county types and the number of dimensions over county characteristics used to demarcate type divisions are endogenously located; this is one of the advantages of using factor analysis instead of cluster analysis.

To determine the number of county types present in the data, we use the maximum likelihood based factor analysis (using the oblique varimax rotation option) technique available in Stata to cluster the 159 counties in ways unobserved by the researcher. Our assignment of counties endogenous to different types seems to be an obvious extension of: Abraham, Goetzmann, and Wachter (1994), who use a k-means clustering algorithm to endogenously locate homogenous groupings of metropolitan housing markets; Lipscomb and Farmer (2005), who use principal components analysis coupled with iterative hedonic regression models to endogenously locate household submarkets in a single neighborhood; and Sutton and Day (2004), who create a seven-layer typology based on U.S. counties with above average population growth. Despite the limitations of factor analysis, we use it primarily to condense a set of related attributes into a smaller set of factors; this allows for counties to load on more than one factor, an association we might miss by using cluster analysis. Compared to other empirical techniques like $k$-means and $k$-medians cluster analysis that were considered, factor analysis provides us a slightly clearer rubric by which to determine cut-off eigenvalues for county type determination. $k$-means and $k$ medians clustering is more appropriate when the researcher has more information about the expected number of final county groups (e.g. Sutton and Day, 2004). In this study, our only expectation is that some larger urban counties will emerge as a "type" based on theories of urban agglomeration. Beyond that, we have no other expectations regarding the final number of county types.

(C) Southern Regional Science Association 2010. 
In this paper, we first use 29 candidate variables (those listed in Table 1) that represent the maximum county diversity profile in a factor analysis, producing 29 factors. The KaiserMeyer-Olkin measure of sampling adequacy suggests that these 29 variables have enough in common to warrant a factor analysis (average K-M-O statistic $=.795$ ). Of these factors, only seven have eigenvalues greater than one, which suggests that the number of county diversity factors can be reduced to seven without sacrificing too much of the explained cumulative variation. These seven factors explain 69.8 percent of the cumulative variation. At this point, it is common for researchers to use the newly created factors as independent variables in regression analyses. In this paper, as a second step, we go further; counties are matched to one of the seven factors that best describes them based on factor scores. This matching process is based on the following statistic akin to a $Z$-statistic:

$$
\text { (3) } T_{i}=\left|\left(\hat{f}_{\text {in }}-\bar{f}_{i}\right) / \hat{\sigma}_{i}\right| \text {, }
$$

where $\hat{f}_{\text {in }}(i=1$ to $7 ; n=1$ to 159$)$ is the factor score for each observation, $\bar{f}_{i}$ is the mean factor score for each type $i$, and $\hat{\sigma}_{i}$ is the standard deviation for each type $i$. Unbiased factor scores using the Bartlett (1951) method were used to calculate $\hat{f}_{i n}, \bar{f}_{i}$, and $\hat{\sigma}_{i}$, which are the three components in this pseudo $Z$-statistic calculation. Then, for each of the 159 observations, the maximum value of $T_{i}\left(T_{1}\right.$ through $\left.T_{7}\right)$ is used to sort counties into types. For example, the highest value of $T_{i}$ for Lowndes County in the dataset is $T_{3}$; so this observation is sorted into Type 3. Repeating this step for all observations gives us the following breakdown for the seven county "types":

$$
\begin{aligned}
& \text { Type } 1-2 \\
& \text { Type } 2-39 \\
& \text { Type } 3-36 \\
& \text { Type } 4-12 \\
& \text { Type } 5-27 \\
& \text { Type } 6-21 \\
& \text { Type } 7-22
\end{aligned}
$$

In the next section, we present the results of our analysis.

\section{RESULTS}

\subsection{Geographical Clusters}

Figure 1 displays the seven county types in Georgia. Purposefully, we did not require that county aggregations be contiguous. Allowing the data to reveal statistically-based clusters of counties imposes less arbitrariness than pre-specifying contiguity among the counties. Visual inspection of Figure 1, coupled with descriptive statistics presented in Table 2, shows several interesting results. First, Type 1 counties (Fulton and Gwinnett) are clustered around the Atlanta MSA and are classified as large urban counties. These counties have the lowest average HHIs for employment mix (index $=.08$ ) and for buying power by race (index $=.62$ ), which suggests that Type 1 counties exhibit a high degree of employment and consumer purchasing power 


\section{FIGURE 1: County Typology for Geogia}
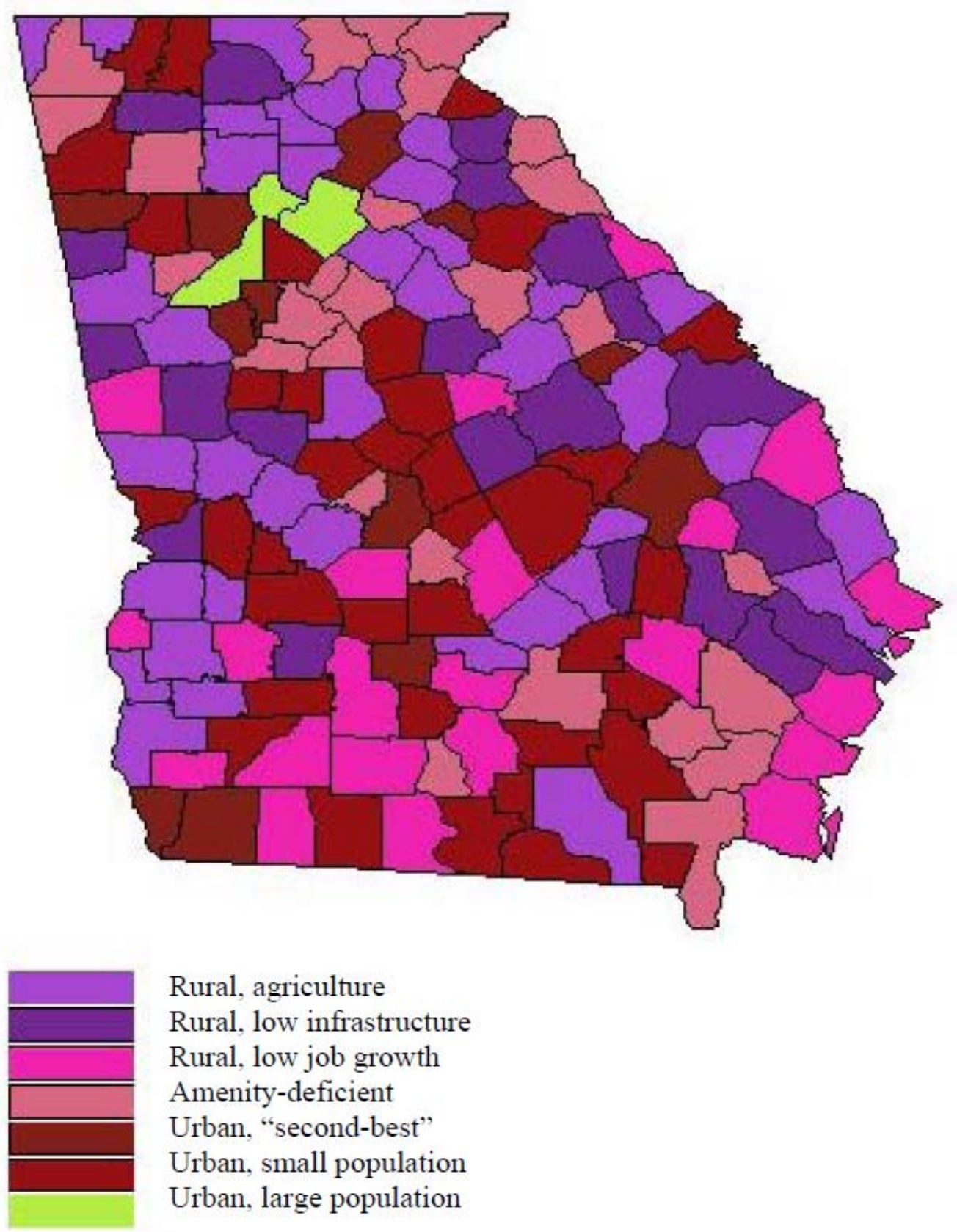

Rural, agriculture

Rural, low infrastructure

Rural, low job growth

Amenity-deficient

Urban, "second-best"

Urban, small population

Urban, large population

(C) Southern Regional Science Association 2010. 
TABLE 2. Means of Study Variables by County Type

\begin{tabular}{lrrrrrrr}
\hline \hline & Type 1 & Type 2 & Type 3 & Type 4 & Type 5 & Type 6 & Type 7 \\
$(N=2)$ & $(N=39)$ & $(N=36)$ & $(N=12)$ & $(N=27)$ & $(N=21)$ & $(N=22)$ \\
\hline LOTTERY & 269.5 & 398.5 & 377.5 & 376.5 & 387.8 & 375.6 & 519.5 \\
BANKRUPT & 7.7 & 8.0 & 8.6 & 8.7 & 9.7 & 7.93 & 8.7 \\
AVGWAGE & 938.00 & 523.5 & 529.1 & 630.8 & 536.0 & 540.4 & 500.8 \\
MEDRENT & 766.5 & 419.1 & 414 & 551.8 & 458.2 & 415.0 & 390.1 \\
PROPVAL & 161,400 & 86,130 & 74,286 & 96,400 & 85,588 & 75,123 & 71,177 \\
OWNRATE & 62.2 & 77.5 & 72.7 & 69.1 & 76.8 & 70.7 & 72.7 \\
PCDEPOSIT & 34,810 & 11,249 & 12,928 & 14,317 & 13,595 & 10,905 & 11,977 \\
PCGOVT & 3,476 & 2,611 & 2,869 & 3,044 & 2,621 & 2,462 & 2,883 \\
FISCAL & 130 & 81.9 & 82.9 & 91.3 & 87.6 & 96.9 & 78.7 \\
MILLAGE & 33.2 & 26.9 & 27.65 & 28.9 & 26.2 & 25.9 & 27.2 \\
HEALTH & 46,213 & 6,117 & 35,908 & 110,952 & 9580 & 5,328 & 18,749 \\
SPLOST & 97,266 & 3,640 & 6,505 & 11,283 & 5,400 & 2,945 & 5,171 \\
WATER & 5.0 & 4.6 & 4.6 & 6.5 & 4.2 & 8.1 & 36.3 \\
STRATIO & 14.4 & 14.5 & 14.9 & 14.5 & 14.5 & 14.6 & 14.2 \\
AYPO5O6 & 81.5 & 71.2 & 75.8 & 77.1 & 80.8 & 75.5 & 77.4 \\
CRIME & 5,283 & 1,802 & 3,200 & 3,223 & 2,575 & 2,669 & 2,697 \\
HAZWASTE & 37.0 & 1.4 & 2.8 & 6.8 & 2.4 & 1.0 & 2.5 \\
DOCTORS & 289.6 & 77.5 & 157.0 & 147.9 & 102.4 & 88.6 & 114.2 \\
INDMIX & .08 & .16 & .17 & .14 & .15 & .19 & .16 \\
CROPLAND & 2,268 & 14,848 & 21,402 & 16,333 & 13,696 & 18,563 & 42,547 \\
RETPULL & 1.2 & .66 & .90 & .97 & .86 & .69 & .87 \\
BLDGPERM & 13,838 & 574.9 & 319.5 & $1,412.8$ & 535.7 & 201.2 & 315.8 \\
AIRPORTS & 1.0 & .51 & .61 & 1.1 & .63 & .57 & .86 \\
BUYPOWER & .62 & .71 & .66 & .66 & .73 & .70 & .64 \\
POPDEN & $1,705.2$ & 106.8 & 137.7 & 730.1 & 158.9 & 64.5 & 78.7 \\
UNEMPLOY & 5.3 & 5.6 & 5.6 & 5.4 & 5.7 & 6.1 & 5.5 \\
HSNONCOMP & 14.3 & 29.7 & 30.4 & 24.2 & 29.1 & 29.1 & 30.9 \\
\%REPUB & 55.0 & 59.8 & 58.2 & 56.6 & 62.6 & 60.4 & 57.1 \\
VOTERS & 383,963 & 17,837 & 20,354 & 89,689 & 20,205 & 11,360 & 16,002 \\
\hline \hline & & & & & & & \\
& & & & & &
\end{tabular}

diversification. The highest factor loadings (available upon request) for these counties are SPLOST dollars collected (.75), average weekly wage (.86), number of hazardous waste sites (.87), number of building permits (.95), population density (.74), and number of registered voters (.88). Evidence supporting the theory of agglomeration for this type includes the highest average weekly wages across all industries $(\$ 938)$, highest average total deposits per capita $(\$ 12,611)$, highest average population density $(1,705)$, lowest average high school non-completion rate (14.3 percent), highest average percentage of schools achieving Annual Yearly Progress (81.5 percent), and the highest average fiscal capacity index value (index $=130$ ). Difference-of-means tests suggest that these two counties have significantly different wages, building permit activity, and population density than the rest of the Georgia county types.

Second, Type 2 counties show at least two distinct clusters - one in the western part of Georgia and the other in the northeastern part of the state. From these two clusters we observe that these counties are contiguous to some of the larger MSAs (the Savannah MSA, the Columbus MSA, the Athens MSA, the Gainesville MSA, and the Chattanooga, Tennessee 
MSA); we classify these counties as rural agricultural counties. The highest factor loadings used to create this county type are median property value (.61), the HHI of buying power by race (.83), the unemployment rate (-.73), and the percentage of votes cast "Republican" in the 2004 General Election (.89). Generally, these counties are rural, ethnically homogeneous (strong concentration of buying power by white residents), and based on farming industries. Type 2 counties have the highest average homeownership rate (77.5 percent), the lowest average percentage of schools achieving Annual Yearly Progress (71.2 percent), the lowest average crime rate index (1,802 per 100,000 population), the lowest average number of physicians index (77.5 per 100,000 population), the lowest average total retail sales pull factor (.66), and the lowest average number of general aviation airports (.51). In fact, the descriptive statistic Moran's (1950) I (available upon request), using a first-order contiguity spatial weights matrix, tells us that the data exhibit positive spatial autocorrelation in the following variables: LOTTERY to PROPVAL; PCDEPOSIT, FISCAL, MILLAGE, and SPLOST; WATER and HAZWASTE; INDMIX, CROPLAND, and BLDGPERM; and BUYPOWER to VOTERS. This means that nearby counties have similar profiles to counties of interest in these variables. Other research on these data (in progress) incorporates space explicitly into regression models seeking to predict county population and income growth rates.

Third, Type 3 counties are urban counties with relatively small populations that generally focus on the education and health sectors. The highest factor loadings used to create Type 3 counties are government expenditures per capita (.67), the total index crime rate (.66), the number of physicians per 100,000 population (.70), the retail sales pull factor (.80), and the number of public general aviation airports (.69). Descriptive statistics suggest that these counties have the highest average pupil-to-teacher ratio (14.9 students per teacher), below average percentage of schools achieving Annual Yearly Progress (75.8 percent), below average number of building permits (319.5), below average population density (137.7), and above average percentage of the population that did not compete high school (30.4 percent). In addition, the majority of these "small urban centers" (Sutton and Day, 2004) contain regional hospitals as well as regional colleges and universities, including Albany State University (Albany), Valdosta State University (Valdosta), South Georgia College (Douglas), Georgia Highlands College (Rome), Augusta State University (Augusta), Abraham Baldwin Agricultural College (Tifton), and Macon State College (Macon).

Fourth, Type 4 counties include other urban centers (Athens, Marietta, Gainesville, and Perry) that do not show any spatial clustering. The highest factor loadings used to create these "second best" counties are median rent (.52), local government direct expenditures for health and hospitals (.66), and population density (.51). The 12 counties classified into Type 4 have the highest average local government direct general expenditures for health and hospitals $(\$ 110,952,000)$, the highest average number of general aviation airports $(1.1)$, as well as the second highest average retail trade pull factor (.97), second highest average SPLOST revenues $(11,283)$, and second highest average number of building permits $(1,412.8)$. These counties also have the second highest average population density (730.1), second lowest average unemployment rate (5.4 percent), and the second highest average number of registered voters (89689). Compared to Type 1, Type 4 counties rank second in many variables used in the county typology determination process.

Type 5 counties may be classified as dynamic, or influenced by changes in the regional and national economy. These counties have the highest average number of bankruptcy filings 
per 100,000 population (9.7), the smallest average area of the counties covered in water (4.2 square miles), the highest average HHI for buying power by race (.73), and the highest average percentage of votes cast for the 2004 Republican presidential candidate (62.6 percent). The highest factor loadings used in the creation of Type 5 are bankruptcy filings per 100,000 population (.75) and pupil-to-teacher ratio (.59).

Type 5 counties exhibit four geographical clusters. The first cluster appears in the Northeast Georgia mountain counties, which have the smallest percentage of land area covered in water. The second cluster appears in Northwest Georgia in the counties that surround the Rome MSA. The third cluster appears in the southeast portion of the Atlanta MSA; and the fourth cluster occurs in the counties contiguous to the counties that abut the Atlantic Ocean. These counties seem to exhibit isolated growth and have many recreational opportunities available. Descriptive statistics suggest that these counties have concentrated buying power in whites (who account for a large majority of the population), have a below average number of harvested cropland acres, and are generally "amenity deficient" (i.e. have below average means in the amenity variables).

Sixth, Type 6 counties exhibit only a single cluster around the outer parts of the Savannah MSA. The 21 counties classified into Type 6 have the lowest total deposits per capita $(\$ 10,905)$, the lowest government expenditures per capita $(\$ 2,462)$, the lowest millage rate $(25.9)$, the lowest number of SPLOST dollars $(\$ 2,945,000)$, the fewest hazardous waste sites $(1.0)$, the highest HHI for employment mix (.19), the fewest building permits (201.2), the smallest population density (64.5), the highest unemployment rate (6.1 percent), and the lowest number of active registered voters $(11,360)$. The highest factor loadings used in the creation of Type 6 are the homeownership rate (.44) and fiscal capacity (.66). Generally, it seems that these counties are rural and have below average infrastructure.

Finally, Type 7 counties show two clusters - one on the Georgia coast and the other in south central Georgia. For these rural, low job growth counties (22 of them), the highest factor loadings are the area of the county covered in water (.67) and number of harvested cropland acres (-.61). Descriptive statistics suggest that these counties have the highest average lottery sales per capita (\$519.50), the highest average county area covered by water (36.3 square miles), the highest average number of harvested cropland acres $(42,547)$, and the highest average high school non-completion rate (30.9 percent). These counties also have the lowest average weekly wage $(\$ 500.80)$, the lowest average fiscal capacity (index $=78.7)$, the lowest average pupil-toteacher ratio (14.2), the lowest average median rent $(\$ 390.10)$, the lowest average median property value $(\$ 71,177)$, and the second lowest average population density (78.7). Generally, it seems that these counties exhibit characteristics of farmland communities where work is often valued more than education beyond high school, which may account for the lowest average weekly wage and lowest median rent.

\subsection{County Types and Job Tax Credit Tiers}

From the Georgia Department of Revenue, we obtained job tax credit data by county for the years 2000 to 2005. The use of data during this period allows us to compare our results to those preliminary results found by Ihlanfeldt and Sjoquist (2001), which will be discussed in the next section. Due to the manual processing of each job tax credit application, a two-year lag exists in the data available to the public. Interestingly, we learned that a company can report negative jobs for a given year, especially if a company generated jobs in Year 1 and lost some of 
TABLE 3. Contingency Table of County Types and Job Tax Credit Tiers

\begin{tabular}{|c|c|c|c|c|c|c|c|c|}
\hline & & \multicolumn{7}{|c|}{ County Type } \\
\hline \multirow{5}{*}{$\begin{array}{l}\text { Job Tax } \\
\text { Credit } \\
\text { Tiers }\end{array}$} & & 1 & 2 & 3 & 4 & 5 & 6 & 7 \\
\hline & 1 & 0 & 17 & 18 & 4 & 8 & 10 & 13 \\
\hline & 2 & 0 & 3 & 10 & 2 & 7 & 8 & 6 \\
\hline & 3 & 1 & 11 & 8 & 3 & 7 & 2 & 3 \\
\hline & 4 & 1 & 8 & 0 & 3 & 5 & 1 & 0 \\
\hline
\end{tabular}

those jobs in Year 2. So, if enough companies in a given county lose jobs in a given year, then the Georgia Department of Revenue will report negative jobs created for a given county in a particular year. However, the actual credit realized for a given year may be positive when the jobs created number is negative; this is due to the fact that tax credits are generated by jobs created in previous years (i.e. tax credits are spread out over a five-year period). So, if a company creates a lot of jobs in Year 1 but then eliminates some jobs within the next five years, the actual jobs created number could be negative in the same year in which the tax credit realized remains positive.

The job tax credit data are surprising in several ways. First, of the 159 counties in Georgia, only an average of 71 counties (or 44.7 percent) had businesses that apply for the job tax credit (the range is 68 to 73 counties) during this period. On average, 4,522 net jobs are created per year, yielding average realized tax credits of $\$ 19.1$ million per year. Using data from 1991 to 1997 reported by Ihlanfeldt and Sjoquist (2001), an average of 4,829 net jobs were created per year, yielding average realized tax credits of $\$ 13.1$ million per year. So, while the number of tax credit dollars has improved on average since 2000, it seems that net jobs created on average have not improved since the previous period. A policy that is very cumbersome, time intensive, and difficult to understand may meet resistance from businesses. The data suggest that this remains the case for the current job tax credit policy in Georgia.

Additionally, we believe that the job tax credit tiers and county types are not independent of each other. To test this hypothesis, $\chi^{2}$ statistics are used to test the null hypothesis of independence between the county type and job tax credit tier classifications. Treating each tax credit tier as a separate unit of analysis, we find in Table 3 the $\chi^{2}$ statistics for Tiers 1 through 4 (with six degrees of freedom) to be $26.2(p=.0001), 14.94(p=.03), 16.4(p=.015)$, and 20.85 $(p=.002)$, respectively. This suggests dependence between these two classification schemes.

\section{DISCUSSION}

\subsection{An Alternative Policy Specification}

It seems that the principal objective of Georgia's BEST program (one part of which is the job tax credit program), created by law in 1994, is to address chronic underlying economic development conditions, "not cyclical fluctuations in economic conditions" (Ihlanfeldt and Sjoquist, 2001, p. 224). This is the reason why so many different variables are used in the county type determination process and why the current tier classification system does not seem to be working well - the latter does not capture the inherent differences in some counties to have different capacities to raise revenue, to construct large industrial parks, to have abundant water resources, etc. Measured in terms of net job creation and tax credits realized, our analysis of the 
job tax credit policy coincides with that of Ihlanfeldt and Sjoquist - it is not very effective. We have discovered also that job tax credit tiers are not independent from county types. Dependence between these two classification systems suggests that we might preserve the same basic ordering of counties (compared to the current three-criteria, four tier system) but be able to capture more specific differences between counties that eliminate the disincentive counties face if their tier status changes. We believe that the use of more county-level variables permits a more detailed examination of the differences between counties and classifies counties into types that are more homogeneous than tiers; this outcome can be used to inform Georgia's job tax credit policy and avoid possible issues associated with firms that may respond strategically to surveys used to collect data (Ihlanfeldt, 1995).

Also, we notice that very few counties are reclassified from one tier to another during the study period. This suggests that counties' economic performances do not change that much, a finding consistent with Ihlanfeldt and Sjoquist (2001). Of the businesses that participate in the job tax credit program, slightly more than one-third (38 percent) come from Tier 1 counties, 26 percent from Tier 2 counties, 22 percent from Tier 3 counties, and 14 percent from Tier 4 counties. The decrease in the percentage of businesses as tier classification increases might suggest that 1) the marginal cost to businesses of completing paperwork is greater than the dollar value of each tax credit received and/or that 2) businesses may choose to locate to nearby counties with a more favorable tier status. For example, Pike County is classified into Tier 3 and has never had a company apply for job tax credits. The counties that surround it are classified as Tier 1 (Meriwether and Upson) or Tier 2 (Lamar and Spalding) throughout the entire time period. The Tier 1 counties have businesses that received 339 net job tax credits during that time; the Tier 2 counties realized -496 job tax credits during that time. As a result, companies looking to locate to the general region seem to be locating to the nearby Tier 1counties. Due to the higher job tax credits, possibly this decision will make these companies profitable sooner. To prevent this more favorable tier status for nearby counties, one suggestion is for the State of Georgia to decrease the difference between the tax credits awarded per job created. The current system offers a maximum tax credit of $\$ 3,500$ (for Tier 1 counties) to a minimum of $\$ 750$ (for Tier 4 counties), a 78 percent difference. For a new company moving to Georgia that creates 500 jobs, this results in a $\$ 1.375$ million incentive to choose the Tier 1 county, all else held constant. A new system, based in part on the county typology classification scheme and on offering tax credits of smaller differences between tiers (e.g. a consistent between-tier \$250 difference per job created), would likely be preferable because a change in tier status should not force a county to lose companies to nearby counties based on that criterion alone. Under this scheme, the difference between the maximum and minimum tax credit $(\$ 3,500$ and $\$ 2,000)$ is only 42.8 percent.

Lastly, we provide a proof of concept. Let us revisit Table 3 briefly. For Type 1 counties, we see that they are distributed across Tiers 3 and 4, which offer companies the lowest job tax credit; this is consistent with the job tax credit policy's focus on rural counties. For other types, like Type 7 , we see that the large majority of these counties is classified into Tier 1 , the tier that offers the highest job tax credits. Simply, we see a general pattern that lower tax credit tiers correspond roughly to higher county types. So, one option for changing the job tax credit system is to have more categories (7) and to decrease the difference between the categories (which will reduce the disincentive for counties that move to a higher tier). Table 4 below illustrates the point-in-time cost savings to the state if we use seven categories. Table 4a uses data sorted by tax credit tier (and Table $4 \mathrm{~b}$ uses the same data sorted by county type) on the 68 
TABLE 4a. Realized Credits, Sorted by Job Tax Credit Tier, 2005

\begin{tabular}{|c|c|c|c|c|}
\hline $\begin{array}{l}\text { (1) } \\
\text { Tier } \\
\end{array}$ & $\begin{array}{c}(2) \\
\text { Credit } \\
\text { per Job }\end{array}$ & $\begin{array}{c}(3) \\
\text { Average Net } \\
\text { Jobs Created, } 2005\end{array}$ & $\begin{array}{c}(4) \\
\text { Number of } \\
\text { Counties }\end{array}$ & $\begin{array}{c}(5) \\
\text { Realized } \\
\text { Credits } \\
\end{array}$ \\
\hline 1 & 3,500 & 31.0 & 34 & $\$ 3,689,000$ \\
\hline 2 & 2,500 & 70.2 & 11 & $\$ 1,930,500$ \\
\hline 3 & 1,250 & 35.5 & 16 & $\$ 710,000$ \\
\hline 4 & 750 & 21.5 & 7 & $\$ 112,875$ \\
\hline Total & & & 68 & $\$ 6,442,375$ \\
\hline
\end{tabular}

TABLE 4b. Realized Credits, Sorted by County Type, 2005

\begin{tabular}{lcrrr}
\hline \hline$(1)$ & $\begin{array}{c}(2) \\
\text { Credit } \\
\text { Type }\end{array}$ & $\begin{array}{c}(3) \\
\text { Average Net Jobs } \\
\text { Created, 2005 }\end{array}$ & $\begin{array}{c}\text { Number of } \\
\text { Counties }\end{array}$ & $\begin{array}{c}\text { (5) } \\
\text { Realized } \\
\text { Credits }\end{array}$ \\
\hline 1 & $\$ 2,000$ & 297.5 & 2 & $\$ 1,190,000$ \\
2 & $\$ 2,250$ & 7.6 & 10 & $\$ 171,000$ \\
3 & $\$ 2,500$ & 16.2 & 16 & $\$ 648,000$ \\
4 & $\$ 2,750$ & 19.5 & 8 & $\$ 429,000$ \\
5 & $\$ 3,000$ & 11.9 & 14 & $\$ 499,800$ \\
6 & $\$ 3,250$ & 6.9 & 10 & $\$ 224,250$ \\
7 & $\$ 3,500$ & 16.8 & 8 & $\$ 470,400$ \\
TOTAL & & & 68 & $\$ 3,632,450$ \\
\hline \hline
\end{tabular}

counties that had businesses apply for job tax credits in 2005. The Realized Credits column (5) is calculated as the product of (2), (3), and (4). What we illustrate here is that using county type redistributes many jobs to the lower credit per job range, which saves the state money at a time when the State's budget is being trimmed at least by 6 percent due to decreased tax revenues (Bluestein, 2008). In particular, a higher number of net jobs created are located in Type 1 counties (Fulton and Gwinnett) and multiplied by a tax credit equal to $\$ 2,000$, whereas before, those same jobs were classified into Tier 4 (where the tax credit per job is $\$ 750$ ). In fact, notice that the Tier 1 counties (34 of them) have realized credits of $\$ 3.68$ million, which is higher than the entire total under the alternative scheme proposed in Table $4 \mathrm{~b}$ ( $\$ 3.63$ million). Also notice that the constant decrease in realized credits under the original scheme (Table 4a, Column 5) does not appear in the alternative scheme (Table 4b, Column 5). What we conclude from this proof of concept is that more categories, a constant decrease in tax credits per job, and a reallocation of counties results in a more even distribution of realized credits across the county types (which might suggest that a change in type status may cause counties to lose fewer businesses to neighboring counties with a more favorable tax credit status) and a lower overall cost to the State of Georgia. We also suggest that this alternative system for calculating tax credits represents a paradigm shift away from focusing on the economic development of poor performing counties and toward the acknowledgement that each job attracted to Georgia, 


\section{FIGURE 2. Commuting Zones of the USDA's Economic Research Service}

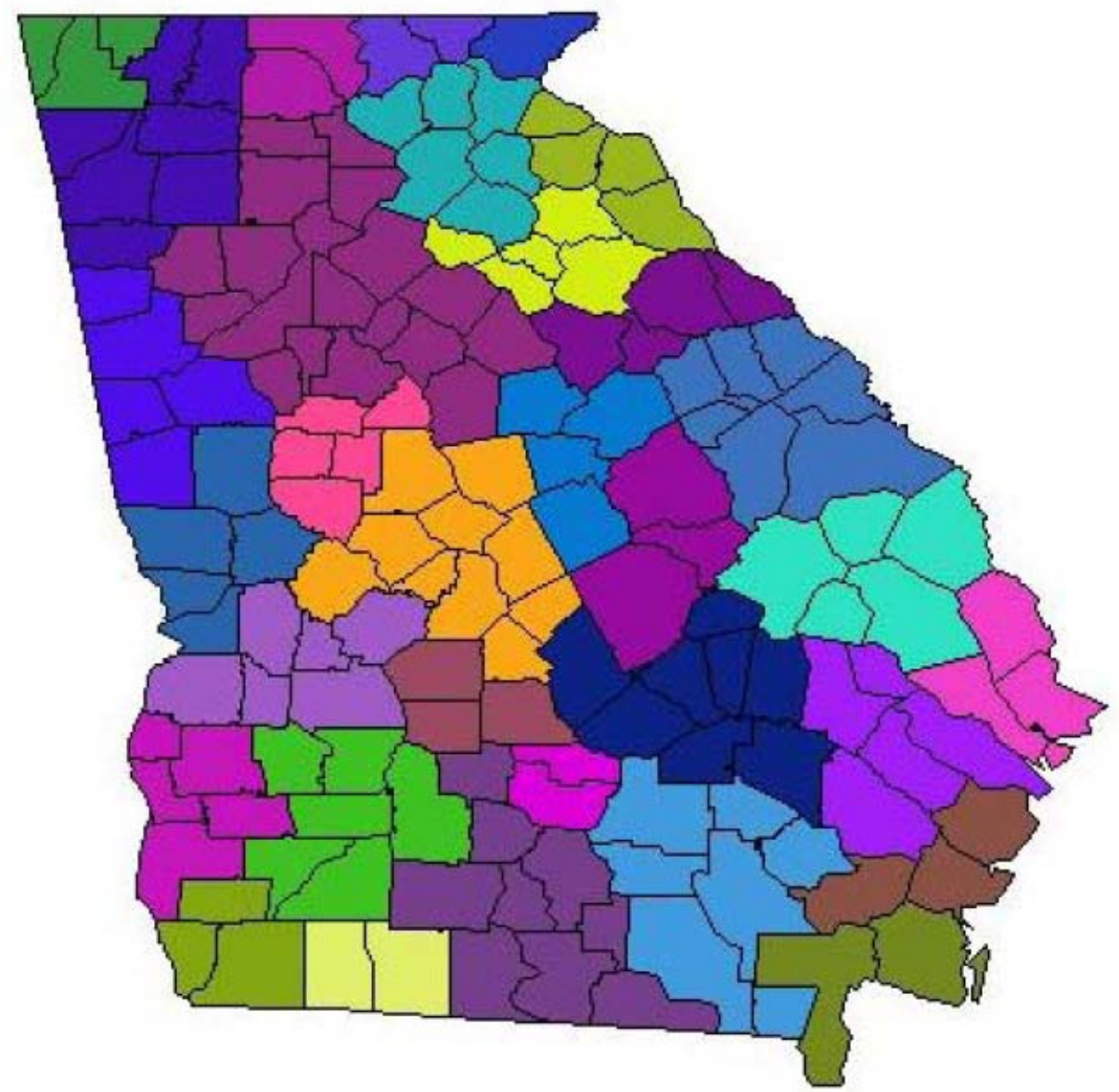

regardless of county, helps improve its regional and global competitiveness (Sjoquist, Smith, and Thomas, 2000).

\subsection{Aggregation Reconsidered}

As a final point, our results suggest something interesting for regional scientists interested in issues related to aggregation. Using the U.S. Department of Agriculture Economic Research Service (USDA-ERS) 1990 Commuting Zones (the most recent available), we compare our county typology to these zones. In Georgia, 32 commuting zones were identified by the USDA-ERS using the Census Bureau's Journey-to-Work files; a few of these zones (e.g. counties near Jacksonville, Florida, and Chattanooga, Tennessee) are associated with urban centers in neighboring states. Using a side-by-side comparison of county types (Figure 1) with commuting zones (Figure 2), we notice that the outcomes are very different. The use of commuting data essentially dictates that commuting zones be contiguous, whereas the use of county typologies does not impose that restriction. Figure 2 seems to suggest that higher levels of aggregation (up to the "supercounty" or "regional" level) might dilute the differences we find using county-specific data in many dimensions. Plus, for county government officials interested 
in benchmarking, the county typology method provides a reasonable way to determine those benchmark counties against which a given county may be compared.

Overall, we believe the aggregation issue comes down to a theoretical difference between regional scientists: policy recommendations at a "supercounty" or "regional" level require data at a different level of aggregation than policy recommendations at a county or even sub-county level. Certainly, this makes the generalizability of our county typology findings somewhat difficult for states, for example, where the average county size is twice that of Georgia's average county size. Yet, we believe that the job tax credit analysis using a county typology lens has many benefits to regional scientists.

\section{CONCLUSION}

In this paper, we have revisited the topic of Georgia's job tax credit policy. Similar to the findings of Ihlanfeldt and Sjoquist (2001) and Morse (1996), we find the current job tax credit policy to be ineffective. Where we diverge from previous research is in the methodology used to create a county typology through which we view the tax credit policy. The justification of the county typology methodology rests with the original intent of the job tax credit policy - to address chronic underlying economic development conditions. We achieve this by utilizing variables that address many facets of counties (fiscal conditions, amenities present, socioeconomic factors, industry characteristics, and demographic factors). Interestingly, some geographical clusters of counties emerge despite the fact that we did not impose this restriction $a$ priori.

This research will be useful to economic developers interested in benchmarking, state government officials interested in making the job tax credit policy more effective and available to more businesses, and regional scientists seeking to answer questions about different levels of aggregation and the policy implications of those different levels. While currently there is no pressure to change the system, Georgia's state budget crisis coupled with a natural curiosity about the policy and its implications for counties that are successful in the attraction of new businesses is the motivation for this study.

\section{REFERENCES}

Abraham, Jesse M., William N. Goetzmann, and Susan M. Wachter. (1994) "Homogeneous Groupings of Metropolitan Housing Markets," Journal of Housing Economics, 3, 186206.

Bartlett, Maurice S. (1951) "The Effect of Standardization on a $\chi^{2}$-Approximation in Factor Analysis," Biometrika, 38, 337-344.

Bluestein, Greg. (2008) "Georgia Agencies Preparing to Impose Sharp Budget Cuts," Forbes.com, Aug 15.

Faulk, Dagney. (2002) "Do State Economic Development Incentives Create Jobs? An Analysis of State Employment Tax Credits," National Tax Journal, 55, 263-280.

Georgia Department of Community Affairs. Georgia Job Tax Credit Program. (2008) Available at: http://www.dca.state.ga.us/economic/taxcredits/programs/taxcredit.asp, February.

(C) Southern Regional Science Association 2010. 
Humphries, Jeffrey M. (2007) "The Multicultural Economy 2007," Georgia Business and Economic Conditions, 67, 1-15.

Ihlanfeldt, Keith R. (1995) "Ten Principles for State Tax Incentives," Economic Development Quarterly, 9, 339-355.

Ihlanfeldt, Keith R. and David L. Sjoquist. (2001) "Conducting an Analysis of Georgia's Economic Development Tax Incentive Program," Economic Development Quarterly, 15, $217-228$.

Lipscomb, Clifford A. and Michael C. Farmer. (2005) "Household Diversity and Market Segmentation in a Single Neighborhood," Annals of Regional Science, 39, 791-810.

Moran, Patrick A.P. (1950) "Notes on Continuous Stochastic Phenomena," Biometrika, 37, 1723.

Morse, Steve. (1996) "Georgia Jobs Tax Credits: Needed Incentives or Needless Subsidies?" unpublished paper. Georgia Public Policy Foundation: Atlanta.

Palmquist, Raymond B. (2004) "Property Value Models," in Karl-Goran Mäler and Jeffery Vincent, eds, Handbook of Environmental Economics, Volume 2. North-Holland: Amsterdam, pp. 763-819.

Putnam, Robert D. (2007) "E Pluribus Unum: Diversity and Community in the Twenty-first Century - The 2006 Johan Skytte Prize Lecture," Scandinavian Political Studies, 30, 137-174.

Samuelson, Paul A. (1954) “The Pure Theory of Public Expenditures," Review of Economics and Statistics, 36, 387-389.

Sjoquist, David L., William Smith, and Kathleen Thomas. (2000) "A Profile of Georgia's Economic Performance and Competitiveness," Georgia State University Fiscal Research Program Report 41, Atlanta.

Sutton, Paul D., and Frederick A. Day. (2004) "Types of Rapidly Growing Counties of the U.S., 1970-1990," Social Science Journal, 41, 251-265.

Tiebout, Charles. (1956) "A Pure Theory of Local Expenditures," Journal of Political Economy, $64,416-424$.

Maxwell, Amanda E., and Richard F. Winters. (2004) "A Quarter-Century of (Data on) Political Corruption in the American States." Paper presented at the Midwest Political Science Association, Chicago.

University of Georgia. (2008) Georgia Statistics System. Available at http://www.georgiastats.uga.edu, last accessed in January 2010. 